\title{
Impact of the winter North-Atlantic weather regimes on subtropical sea- surface height variability
}

\author{
Nicolas Barrier ${ }^{1,{ }^{*}}$, Anne-Marie Treguier ${ }^{1}$, Christophe Cassou ${ }^{2}$, Julie Deshayes ${ }^{1}$ \\ ${ }^{1}$ Laboratoire de Physique des oceans, CNRS-Ifremer-UBO-IRD, UMR 6523, Brest, France \\ ${ }^{2}$ CNRS Cerfacs, Toulouse, France \\ *: Corresponding author : Nicolas Barrier, email address : Nicolas.Barrier@ifremer.fr
}

\begin{abstract}
:
Interannual variability of subtropical sea-surface-height (SSH) anomalies, estimated by satellite and tide-gauge data, is investigated in relation to wintertime daily North-Atlantic weather regimes. Sealevel anomalies can be viewed as proxies for the subtropical gyre intensity because of the intrinsic baroclinic structure of the circulation. Our results show that the strongest correlation between SSH and weather regimes is found with the so-called Atlantic-Ridge (AR) while no significant values are obtained for the other regimes, including those related to the North Atlantic Oscillation (NAO), known as the primary actor of the Atlantic dynamics. Wintertime AR events are characterized by anticyclonic wind anomalies off Europe leading to a northward shift of the climatological wind-stress curl. The latter affects subtropical SSH annual variability by altered Sverdrup balance and ocean Rossby wave dynamics propagating westward from the African coast towards the Caribbean. The use of a simple linear planetary geostrophic model allows to quantify those effects and confirms the primary importance of the winter season to explain the largest part of SSH interannual variability in the Atlantic subtropical gyre. Our results open new perspectives in the comprehension of North-Atlantic Ocean variability emphasizing the role of $A R$ as a driver of interannual variability at least of comparable importance to NAO.
\end{abstract}

\section{Introduction}

In the context of climate change, the detection of multi-decadal trends and their potential attribution to human influence is a major challenge. A special attention is devoted to sea-surface height (SSH) that integrates the forcings, whatever their origins (natural such as volcanic/tropospheric aerosols and solar fluctuations, or anthropogenic such as sulfates and greenhouse gazes emission, etc.), over long periods of time. Its recent accelerating rise is expected to have regionally potential disastrous impacts. Observed SSH variability from seasonal to decadal timescales can be considered as a superimposition of a global upward trend in response to external forcings and a signal associated with intrinsic or natural variability of the climate system. The latter is due to the coupling between components of very different time-scale and spatial-scale characteristics of variability and to the presence of nonlinear processes. Its variance is presently one order of magnitude larger than the externally-forced component and it is thus necessary to quantify and understand the mechanisms of that natural variability to be able to remove it from the observed records and assess long-term trends. In the North-Atlantic, ocean 
41 variability mostly comes from changes in wind and buoyancy forcings related to

42 large-scale modes of atmospheric variability. From daily to decadal timescales,

43 the North-Atlantic Oscillation (NAO) is the dominant pattern in the Northern

${ }_{44}$ Atlantic/Europe domain. As a matter of fact, many studies were devoted to inves-

45 tigate the impacts of NAO on ocean circulation, especially on SSH and meridional

46 heat transport (MHT) anomalies. MHT anomalies influence basin-scale SSH in

${ }_{47}$ turn, via heat content changes (Hakkinen 1999; Esselborn and Eden 2001). We

48 briefly review, below, a selection that is relevant for our study.

49 Ezer (1999) used sensitivity experiments of an ocean model to surface forc-

50 ing to investigate the variability of the subtropical gyre. His results suggest that

51 changes in wind-patterns in the northeastern Atlantic, that he attributes to NAO,

52 cause negative surface elevation. The proposed mechanism is the westward propa-

53 gation of long Rossby waves, consistently with Cabanes et al (2006) and references

54 therein. Hakkinen (1999) argues from a forced ocean model that the NAO is the

55 dominant forcing of MHT via altered surface forcings (wind-stress and heat fluxes).

56 The author states that MHT immediate response to changes in NAO occurs via

57 anomalous Ekman transport, while the low-frequency response mainly occurs via

58 the integration of NAO-induced heat fluxes in the subpolar gyre and the south-

59 ward export of Labrador Sea Water, that causes MHT anomalies to propagate

${ }_{60}$ from $45^{\circ} \mathrm{N}$ to $25^{\circ} \mathrm{N}$ within one year. Both Eden and Willebrand (2001) and Gulev

61 et al (2003) show an immediate MHT response likely driven by NAO-related wind

62 anomalies. However, their numerical experiments show a delayed ocean response

63 of different nature. While in Eden and Willebrand (2001) the lagged baroclinic re-

64 sponse is mainly wind-driven, Gulev et al (2003) argue that it is due to buoyancy

65 forcing and Labrador Sea Water formation in the subpolar gyre. Esselborn and 
66 Eden (2001) investigate, from satellite data and forced ocean model, basin-scale

67 SSH interannual variability in relation with the NAO. They argue that the im-

68 mediate response to a switch from a positive to a negative NAO phase induces a

69 dipole pattern, with negative anomalies in the subpolar gyre and positive anoma-

70 lies in the subtropical gyre. They propose that NAO-related changes in wind-

71 stress curl leads to ocean circulation anomalies that induces anomalous advection

72 of temperature (term $\overline{u^{\prime} \bar{T}}$ ). This leads to anomalous heat convergence/divergence

73 that in turn induces this SSH dipole pattern. The impacts of NAO on subpolar

74 and subtropical gyres have also been investigated from observations. Curry and

75 McCartney (2001) use observed potential energy anomalies (PEA), that can be

76 reflected in $\mathrm{SSH}$ anomalies, to estimate the impact of NAO on both gyres. They

77 argue that NAO-induced PEA in the subtropical gyre are dominated by vertical

78 displacements of the pycnocline, driven by open-ocean wind-stress forcing inte-

79 grated westward (see also Sturges and Hong 1995; Sturges et al 1998; Hong et al

80 2000). But changes in the Eighteen Degree Water property (Joyce et al 2000) and

81 changes in the deep ocean (due to altered import of Labrador Sea Water, Curry

${ }_{82}$ et al 1998) can also impact this NAO-induced PEA in the subtropical gyre. In the

83 subpolar region, PEA come primarily from changes in local heat fluxes but also

84 from changes in the rates at which the water is imported and exported from the

85 interior basin.

86 As described above, the NAO is an essential driver of both immediate and

87 delayed oceanic variability (see also Lohmann et al 2009). However, recent work

88 of Hakkinen et al $(2011 \mathrm{a}, \mathrm{b})$ suggests that one has to go beyond the sole NAO

89 contribution to understand the observed changes. In particular, the NAO fails

90 to explain the warming and salinization of the early 2000s in the North-Eastern 
91 Atlantic. They argue that the latter could be due to the decadal fluctuations 92 of winter blocking conditions assessed in their study from the NOAA-20CR reanalysis (Compo et al 2011) through traditional atmospheric metrics based on 94 daily variance of mean sea-level pressure (MSLP) anomalies. The blocking associ95 ated space-time structure of wind-anomalies, the so-called "gyre-mode" (Hakkinen 96 et al 2011a), is related to the second mode of variability in the North-Atlantic ${ }_{97}$ atmospheric circulation, the so-called East-Atlantic Pattern (EAP, Barnston and 98 Livezey 1987). When EAP dominates atmospheric variability, the subtropical gyre 99 expands northward and the subpolar gyre shrinks; this facilitates the invasion of

warm, salty subtropical water into the eastern subpolar gyre.

The relative importance of NAO versus EAP atmospheric patterns in forcing ocean circulation thus still appears to be an open question according to the literature. The major goal of this study is to determine which large-scale atmospheric circulation is responsible for the interannual SSH variability in the North Atlantic subtropical gyre estimated from satellite and tide-gauge data. The atmospheric anomalous circulation is assessed here through the weather regime (WR) circulation paradigm, preferred to classical modes of variability. WRs have been thoroughly studied in the literature (Vautard 1990; Michelangi et al 1995, among others) and shown to be very efficient at capturing the interannual variability of the surface ocean forcing in the North Atlantic (Cassou et al 2011). A second objective is to clarify which mechanisms drive the ocean response to changes in atmospheric conditions described by the WRs. The paper is organized as follows. Section 2 describes the data and the methodology used in this study. Section 3 describes the observed winter North Atlantic WR ; a comparison between EOF and WR circulation patterns is provided. Section 4 depicts the relationship between 
WR occurrences and observed subtropical SSH anomalies. Section 5, based on a simple linear planetary geostrophic model, investigates the physical mechanism at work. Conclusions are given in section 6 .

\section{Data and methodology}

\subsection{Subtropical sea-level}

Subtropical sea-level anomalies are extracted from two different datasets. We first use AVISO Maps of Absolute Dynamic Topography (MADT, Ducet et al 2000), available from October, 1992 to March, 2010. MADT maps are first regridded at a coarser resolution $\left(1^{\circ}\right.$, similarly to Cabanes et al 2006). As winter weather regimes occurrences are determined over winter, yearly averaged MADT anomalies are computed from December to Novembre in order to keep the continuity of winter months. As the dataset is not complete in 1992 and 2010, those years are discarded. Additionally, a subtropical MADT time-series is computed by the averaging of MADT anomalies over the box $\left(64^{\circ} \mathrm{W}-73^{\circ} \mathrm{W}, 24^{\circ} \mathrm{N}-30^{\circ} \mathrm{N}\right)$, which encompasses the subtropical gyre core without being influenced by the Gulf-Stream.

As the AVISO yearly time series spans a very short time-period (17 years), it is completed by a longer record. We use tide-gauge data at Bermuda, located in the subtropical gyre. Data were obtained from the Permanent Service for Mean Sea Level (PSMSL, http://www.psmsl.org/), station Esso Pier/St Georges (32.367 ${ }^{\circ} \mathrm{N}$, $\left.64.700^{\circ} \mathrm{W}\right)$, between the period $1949-1998$. To recover the missing values in the PSMSL annual time series, due to some missing data in the monthly records, we proceed as follows. The inverted barometer correction, following Ponte (2006), is first applied to non-missing data of the raw PSMSL monthly time-series. A 
linear trend of $1.2 \mathrm{~mm} /$ year, which is comparable with the existing literature

(e.g. Bindoff et al 2007), is removed from this monthly time series and anomalies are calculated by subtracting the mean seasonal cycle. Values are finally yearly averaged according to the same December-November average convention. We verify that our yearly index, which spans 50 years, is correlated at 0.98 to the one given by PSMSL (not shown).

\subsection{Classification into weather regimes}

The WR framework, based on daily circulation changes, accounts for the existence of preferred large-scale spatial states of the extratropical atmosphere set by the stationary waves (Molteni et al 1990). The WR framework differs from fixed station indices such as the traditional NAO index (Hurrell 1995), polluted by circulations that are unrelated to the latitudinal alternation of the mean westerly flow which defines the NAO itself (e.g Hurrell and VanLoon 1997). It also differs from the traditional decomposition in modes of variability based for instance on EOF or Singular Value Decomposition that makes symmetry assumptions for spatial fluctuations. Additionally, the WR paradigm also accounts for time-scale interaction: weather changes are interpreted as transitions between WR while climate variability is understood in terms of time-integration of daily WR occurrences and internal characteristics (strength for instance) over the time-scale of interest. This temporal integration property is promising for ocean variability studies (Minvielle et al 2011), the ocean being often viewed as the integrator of atmospheric noise (Frankignoul et al 1997). 
To decompose atmospheric variability into WRs, we proceed as follows. NCEPNCAR (Kalnay et al 1996) daily maps of mean sea-level pressure (MSLP) anomalies are computed inside the North-Atlantic domain $\left(20^{\circ} \mathrm{N}-80^{\circ} \mathrm{N}, 80^{\circ} \mathrm{W}-30^{\circ} \mathrm{E}\right)$ by removing a smoothed seasonal cycle (two harmonics retained). Winter (DecemberJanuary-February-March, hereafter DJFM) days are selected and MSLP anomalies are normalized by the cosine of the latitude. The classification is done in EOF space in order to reduce the degrees of freedom and thus facilitate the calculation. 20 EOFs that explain $98.9 \%$ of the total variance are retained. It should be noted that contrary to Ayrault et al (1995) or Smyth et al (1999), no filtering is applied to our data. This allows us to keep the synoptic-scale variability ( $2-6$ days), the slow-synoptic processes $(6-11$ days $)$ and the low frequency variability $(11-30$ days) described in Gulev et al (2002). Part of the ultra-high frequency variability (UHFV, $6 \mathrm{~h}$ to 2 days) is lost by the daily averaging. Even if the variance associated with UHFV is small, associated small scale events can lead to significant winds, which will thus not be considered here.

While there are many classification techniques (mixture model clustering: Smyth et al 1999; non-linear equilibration: Vautard and Legras 1988,Vautard 1990), we use the $k$-mean algorithm described in Michelangi et al (1995) and Cassou (2008), which relies on the recurrence property of the weather regimes. The aim of the method is to agglomerate days that share some resemblance (Euclidian criteria). It assumes that the number of clusters, $k$, is known. The algorithm, described in Michelangi et al (1995), is as follows. $k$ days are randomly chosen among all the dataset and their anomalous circulations define the $k$ centroids $C_{k}$ (initial seeds). Then, the method attributes to each day $x$ the cluster that minimizes the Euclidian distance between $x$ and $C_{k}$, that we call $d\left(x, C_{k}\right)$. This initial partition, 
that we call $P_{k}^{0}$, is used to re-compute the centroids by averaging all the days that belong to the same regime. We call these new centroids $C_{k}^{0}$. The aggregation is iteratively repeated until the sum of variances within clusters of the $n^{\text {th }}$ iteration, defined as:

$$
W\left(P^{n}\right)=\sum_{k=1}^{N} \sum_{x \in C_{k}^{n}} d^{2}\left(x, C_{k}^{n}\right)
$$

reaches a local minimum. As this method strongly depends on the initialization of the algorithm, the entire process is repeated 50 times for as many partitions. The one that minimizes the ratio of the sum of variances within clusters, $W(P)$, on the sum of variances outside clusters, $J(P)$, defined as:

$$
J(P)=\sum_{k=1}^{N} \sum_{x \notin C_{k}} d^{2}\left(x, C_{k}\right)
$$

is selected. Finally, daily occurrences are summed over DJFM days from 1949 to 2010 to obtain a time-series of yearly occurrences for each regime.

One limitation of the $k$-mean algorithm is the assumption that the number of regimes is a priori known. However, Michelangi et al (1995) determined that the number of clusters that allows classificability and reproducibility is 4 , which is the value determined from other methods (Vautard 1990). In the following, we thus retain 4 winter weather regimes. A second limit, as mentioned in Smyth et al (1999), is that this algorithm is inadequate if there is strong overlapping in the spatial patterns of the regimes. Finally, most studies that deal with weather regimes use geopotential height to compute weather regimes (Vautard 1990; Michelangi et al 1995; Smyth et al 1999; Cassou et al 2011). We preferred to use MSLP, similarly with Santos et al (2005), as MSLP can easily be related to surface winds. We checked that comparable centroids and yearly occurrences are obtained using anomalies of geopotential height at $500 \mathrm{hPa}$ (not shown). 
The four winter weather regimes that we obtain are depicted in figure 1 (left panels): the Atlantic Ridge (AR) characterized by an anticyclonic anomaly off Europe, the Scandinavian-Blocking (BLK) dominated by a meridional pressure dipole, north of $40^{\circ} \mathrm{N}$, with an anticyclonic anomaly over northern Europe and a cyclonic circulation between Greenland and Iceland, and the Greenland Anticyclone and Zonal regimes linked to the negative and positive phases of the NAO, respectively. NAO- is characterized by a positive anomaly north of $50^{\circ} \mathrm{N}$ centered around Greenland and aligned at $30^{\circ} \mathrm{W}$ with a negative pressure anomaly south of $50^{\circ} \mathrm{N} . \mathrm{NAO}+$ is dominated by negative anomalies between Iceland and the North Sea while positive anomalies prevail south of $50^{\circ} \mathrm{N}$. As shown in figure 1 (right panels, blue bars), winter occurrences time series highlight a strong interannual to decadal variability with neither pronounced nor significant trends.

Weather regimes have been shown to impact the "storm track" position. Ayrault et al (1995) used the $2-6$ days variance of geopotential height at $500 \mathrm{hPa}\left(Z_{500}\right)$ as a proxy for the eastern position of the jet. The author states that $\mathrm{NAO}+$ and NAO- are more likely to affect northern and southern Europe, respectively, while blocking regimes are likely to impact North-Eastern America. Rudeva and Gulev (2011), using clustering techniques on cyclone observations, suggest that cyclones formed in the Gulf-Stream region under NAO+/NAO- conditions are likely to endup in the Northeastern/Eastern Central Atlantic, respectively. On the other hand, cyclones generated under AR conditions will decay in the Labrador-Sea while cyclones formed under blocking regimes will decay in the Southeastern Atlantic. We performed a similar diagnosis as Ayrault et al (1995) to determine the position of 
the eastern part of the jet within our four regimes. We use NCEP/NCAR (Kalnay et al 1996) $2-6$ days $Z_{500}$ anomalies and computed the standard deviation within each cluster (figure 2, color shading) and compare it with the climatological one (figure 2, black contours). For AR, one can see that the climatological core of variability, localized off North-Eastern America, is tilted toward the Labrador-Sea, consistently with Gulev et al (2002). There is also a core of high standard deviation located in the Irminger Sea. In BLK, we notice that the variability is higher in the North-Eastern America, while there seems to be a Northeastern tilt of the Eastern part of the jet, probably due to the long-lasting anticyclone off Europe (figure 1). The standard deviation in NAO- seems weaker and more zonal, while in $\mathrm{NAO}+$ it has a greater zonal extension. This seemingly implies more cyclones in Northeastern Atlantic, consistent with Rudeva and Gulev (2011).

As described above, the WR paradigm differs from the traditional decomposition in modes of variability, which, by construction, makes symmetry assumptions. Figure 1 (left panels) contrasts the MSLP patterns obtained from winter WR decomposition (color shading) to those of the corresponding modes of variability. The latter are obtained from EOF decomposition (black contours) performed on DJFM averages of MSLP anomalies over the same North-Atlantic domain than the WR. From figure 1, we can infer that AR is the positive phase of the EAP (Barnston and Livezey 1987, $2^{\text {nd }}$ EOF of MSLP) and BLK is the positive phase of the so-called Scandinavian (SCAN) pattern $\left(3^{\text {rd }}\right.$ EOF of MSLP). Finally, NAOand $\mathrm{NAO}+$ project respectively on the positive and negative phases of the NAO $\left(1^{s t}\right.$ EOF of MSLP). From figure 1, it is worth noticing that the spatial symmetry assumption is not valid for the NAO. Indeed, the spatial pattern of $\mathrm{NAO}_{E O F}$ is closer to $\mathrm{NAO}_{-}{ }_{R}$ than to $\mathrm{NAO}+_{W}$ obtained from classification: the $\mathrm{NAO}+_{W}$ 
northernmost negative anomaly is shifted eastward and the southernmost positive anomaly is tilted south-eastward. Such a difference is associated with the intrinsic dynamics of the upper-level tropospheric jet and is inherent to the two states of its latitudinal position (Cassou et al 2004). as the $1^{\text {st }}$ normalized principal component of MSLP anomalies) and NAO+ $W R$ occurrences is 0.67 while the correlation between $\mathrm{NAO}_{E O F}$ index and NAO- $W R$ oc253 SCAN-EOF (by construction).

currences is higher and reach -0.89 . Regarding $\mathrm{AR}_{W R}$ regime, there is a good cor-

respondance with the $\mathrm{EAP}_{E O F}$ pattern, although the maximum positive anomaly is shifted North-Eastward in $\mathrm{AR}_{W R}$ compared to $\mathrm{EAP}_{E O F}$; as expected, the two time-series are well correlated $(\mathrm{R}=0.75)$. The SCAN pattern is somehow different from BLK and the two time series are less correlated. A possible cause for this discrepancy is the orthogonality constraint of the EOF decomposition and also the fact that "inverse blocking" events do not exist in nature as opposed to

To summarize, the consideration of winter WR rather than the consideration of classical EOF modes of variability allows to take into account the NAO spatial asymmetry, the sole existence of blocking states without any constraint of orthogonality, which could lead to unrealistic spatial patterns. As a consequence, in the following, the atmospheric variability in this study is only assessed through the WR paradigm. 


\section{Subtropical sea-level response to weather regimes}

The impact of wintertime WRs on sea-level anomalies can occur via mechanisms of different nature. At seasonal and interannual timescales, the so-called inverted barometer effect links SSH variations in ocean basins to the variation of surface atmospheric pressure (Ponte 2006; Tsimplis and Shaw 2008; Woodworth et al 2010, and references therein). This effect is not considered here as inverted barometer corrections have been applied to the sea-level observations.

Weather regimes are associated with wind-anomalies (consistent with MSLP patterns, figure 3, black arrows) and air-temperature anomalies (not shown), that are traditionnaly assessed by daily composites. AR is dominated by a strong anticyclonic anomaly off Europe and by a surface warming centered at the intergyre region and extending in the north-western subpolar gyre. BLK depicts anticyclonic anomalous circulation centered on Europe that prevents the mean Westerlies to penetrate inland. Temperatures are colder off Newfoundland while warmer conditions occur in the GIN seas due to the low-level advection of warm air from the South. NAO- (resp. NAO+) is characterized by a reduction (resp. strengthening) and southward (northward) shift of the mean Westerlies and the Trade winds in the subtropics that imprint a tripolar temperature pattern in latitude (Cayan 1992), with a warming (resp. cooling) in the Labrador Sea/subtropics and a cooling (resp. warming) in the GIN seas and the midlatitudes.

Those wind and air-temperature anomalies can lead to subtropical SSH response via either halosteric/thermosteric effects or the dynamical adjustment to the wind-stress forcing. The first mechanism corresponds to the thermal/haline dilatation of the ocean water column induced by temperature changes (Tsimplis et al 
2006) or changes in the global fresh water budget (e.g. icecaps melting, Stammer

et al 2011). Those changes can be induced either by changes in heat/freshwater fluxes from the atmosphere to the ocean or by anomalous tracer advection. The second mechanism, associated with the long-term changes of open ocean wind stress curl, induces both a barotropic (Sverdrup-like dynamics) and a baroclinic (westward propagation of Rossby waves) ocean response (Sturges and Hong 1995;

(figure 3, color shading) as:

$$
\widetilde{\psi_{S v}}(x, y)=\frac{1}{\rho_{0} \beta} \int_{x_{E}}^{x} \operatorname{curl}_{z}\left(\widetilde{\tau}\left(x^{\prime}, y\right)\right) d x^{\prime}
$$

where $\rho_{0}=1030 \mathrm{~kg} \mathrm{~m}^{-3}$ is the reference density of sea-water, $\beta$ the meridional gradient of the Coriolis parameter, $\widetilde{\tau}$ the wind stress anomaly associated with WRs (figure 3 , black arrows) and $x_{E}$ the position of the Eastern boundary. These anomalies can be related to the mean pattern of the subpolar and subtropical gyre shown in figure 4 .

AR is characterized by strong positive anomalies in the Labrador Sea associated with anomalous southerly winds that contrast with slackened westerlies at midlatitudes (between $20^{\circ}$ and $40^{\circ} \mathrm{N}$ ). BLK anomalies are very weak, except for 
a positive anomaly south of Iceland. NAO- is characterized by a positive anomaly in the northern boundary of the Labrador Sea and Irminger Sea and at $30^{\circ} \mathrm{N}$, and a negative anomaly between $40^{\circ} \mathrm{N}$ and $50^{\circ} \mathrm{N}$ in the intergyre region. NAO+ is characterized by opposite anomalies although shifted southward compared to NAO- in agreement with the spatial asymmetry of the two NAO phases captured through WR. For AR, note that the Sverdrup transport anomalies project very well onto the mean position of the gyres (figure 4a); hence AR is expected to play a central role in the subtropical gyre variability consistently with the (Hakkinen et al 2011a) "gyre-mode" (their figure 3A).

To further estimate the possible roles of WR in forcing the North Atlantic subtropical SSH variability, we calculate the correlations between WR winter occurrences and the annual subtropical SSH anomaly index (after removing a linear trend). A correlation of -0.34 is obtained with AR yearly occurrences over 19932009 , significant at the $80 \%$ level (table 1 ). The confidence interval is computed by a Student test, in which the degree of freedom is multiplied by a correction factor depending on the 1 year-lag autocorrelation of each time series (Bretherton et al 1999, their equation 31). No correlations are found for neither NAO+ or NAOwhile a positive correlation of 0.36 is found with BLK.

As documented earlier, AR regime is characterized by a persistent anticyclonic anomaly off Europe (figure 3) that displaces the climatological zero-wind-stress curl northward (figure 4, left panel, red contours). Considering simple Sverdrup balance, this causes a decrease of subtropical SSH as confirmed in figure 4 (right panel) from MADT composites. The latter are computed for extreme AR years, defined as winters for which the seasonal occurrences are greater than one standard deviation. When AR winter events are frequent, a large scale negative anomaly 

encompasses the subtropical gyre, consistently with the correlation previously discussed. The subpolar gyre is also characterized by positive anomalies that are stronger in its eastern part and indicate a weakening of circulation there. All together, this is consistent with the anomalous Sverdrup contribution from WR wind characteristics as discussed above.

The results presented so far suggest the importance of AR for subtropical SSH interannual variability. However, those could be criticized because of the shortness of the AVISO time series. In order to corroborate our findings, we have used the observed data from tide-gauge at Bermuda (located in the subtropical gyre, figure 3, black point), to compute similar correlations, but over a much longer period of time (50 years vs. 17 years for AVISO). Maximum correlation at -0.39 , significant at the $95 \%$ level, is found again for AR (table 1) and consistently with AVISO, no significant correlations are found for $\mathrm{NAO}+$ and NAO-. The correlation for BLK observed in the AVISO dataset no longer stands $(0.17$, not significant at the $95 \%$ level) and could therefore be attributed to the shortness of the data or to some non stationarity of the ocean-atmosphere relationship yet to be investigated.

The correlations previously described simply give the information that subtropical SSH and AR occurrences significantly covary in time over 1948-1998. No information on the amplitude of the AR-induced SSH anomalies nor on the stationarity of the relationship has been provided so far. The temporal evolution of the

AR-induced signal of Bermuda SSH is now reconstructed (figure 5, solid line) by linearly regressing the normalized AR occurrences onto the SSH index. The regression coefficient estimated over 1948-1998 equals $-17.5 \mathrm{~mm}$ per standard deviation of winter AR occurrences. Light grey bars are the tide-gauge observations which are used for the computation, dark grey bars from 1998 onwards are independent 
data taken from the tide-gauge data but past the missing gap (see PSMSL website). The latter can be used as cross-validation to assess the skill of the method.

The reconstructed signal does capture a large part of the decadal variability up to the mid-70s in agreement with the strong dominance of AR over those decades. While interannual fluctuations in the 80 s and early 90 s are reproduced to some extent, the late 70s SSH significant rise is completely missed. A possible cause is that the late 70s decade is characterized by strong NAO- events between 1977 and 1980 (figure 1) preceded by years of strong BLK. Both have a local imprint around Bermuda (not shown) and may be lowering the impact of AR, that is less frequent in that period. Note that the variance of the reconstructed time series is weaker than the observed one as expected by construction using regression models (von Storch 1999).

\section{Mechanisms of interannual subtropical SSH variability in response}

\section{to WR}

As stated earlier, we propose that subtropical SSH response to WRs is driven by open ocean wind-stress curl. This working hypothesis discards the thermosteric/halosteric effects caused by atmospheric heat/freshwater fluxes and by tracer advection. The correlations discussed in the above seem to indicate that the AR anticyclonic circulation, which tilts the wind-stress curl northward, causes a decrease in SSH yearly anomalies.

In order to test our hypothesis, we have computed the wind-driven barotropic $\eta_{p}$ and baroclinic $\eta_{c}$ components of sea-level from observed daily wind stress curl 
11 and 20):

$$
\begin{gathered}
\eta_{p}(x, y, t)=\int_{x e}^{x} \frac{f^{2}}{H \beta g} \operatorname{curl}\left(\frac{\tau}{\rho_{0} f}\right) \\
\eta_{c}(x, y, t)=-C_{r n}^{-1} \int_{x}^{x_{e}}\left[A_{n} \operatorname{curl}\left(\frac{\tau}{\rho_{0} f}\right)\right]\left(x^{\prime}, y, t-t_{x^{\prime}}\right) d x^{\prime}
\end{gathered}
$$

388 lem: m:

$$
\partial_{z}\left(\frac{f^{2}}{N^{2}} \partial_{z} F\right)+\lambda^{2} F=0
$$

where $t_{x^{\prime}}=\left(x-x_{x^{\prime}}\right) / C_{r n}$ is the propagation time of the wave generated by local atmospheric forcing east of longitude $x, C_{r n}=-\beta / \lambda_{n}^{2}$ is the wave propagation speed of the $n^{\text {th }}$ baroclinic mode (which eigenvalue is $\lambda_{n}$ ) and $A_{n}$ the wind-stress curl projection on this mode. The derivation of those two equations, described in Cabanes et al (2006), relies on planetary geostrophic (PG) dynamics, neglects bottom topography, advection by the mean currents and assumes a rigid lid. The wind-stress forcing is implemented as a body force in the mixed layer of constant depth $(100 \mathrm{~m})$. The values of $\mathrm{C}$ are computed by inversion of the eigenvalue prob-

where $F(z)$ is the vertical baroclinic structure, $\lambda$ the corresponding eigenvalue and $N^{2}$ the Brunt-Vaisala frequency (computed from World Ocean Atlas 2005 climatology Locarnini et al (2006); Antonov et al (2006) following the procedure of Chelton et al (1998)). Equation 6 is verified by an infinity of orthogonal vertical modes but, consistently with Cabanes et al (2006), the first baroclinic mode is found to be dominant in the subtropical area. We consistently discard the higherranked modes in our study. The values of $C$ and $A$ are longitude dependent but, 
similarly to Cabanes et al (2006), we have used their zonal means. The computation has been performed at $(33.3 N,-78.8 \mathrm{~W})$, where $C$ and $A$ are equal to $-0.025 \mathrm{m.s} \mathrm{s}^{-1}$ and $11.10^{-4}$ respectively. We have chosen daily wind fields instead of monthly fields because the latter give too weak an amplitude of SSH (Cécile Cabanes, personal communication) and also to better account for the intrinsic properties and advantages of the WR as above-described. NCEP/NCAR daily wind fields are available from 1948 to 2006. The first five years of the PG sea-level anomalies were discarded as part of the spin-up.

Total (ie. barotropic+baroclinic) contribution of wind-stress curl to sea-level anomalies is depicted in figure 5 (dashed line) and a significant correlation of 0.53 is found with observations (table 1). Note that the amplitude of the barotropic component is approximately 3 times smaller than the baroclinic one (not shown). This is consistent with the results of Hong et al (2000) who argue that, to first order, Bermuda sea-level can be approximated by the first baroclinic mode. Interestingly, when the regression (solid black line) has some skill to reproduce observed SSH variability, so does the PG SSH anomalies. This tends to confirm that AR impact on Bermuda SSH is very likely due to the strong anticyclone off Europe, which tilts the zero wind-stress curl northward, and brings some confidence in our physical interpretation of the observations. Especially, the dramatic drop of 1970 is well captured by the regression and the PG model. This is consistent with Ezer (1999) who argues that the 1970 drop is due to changes in open-ocean wind-stress curl. However, Ezer (1999) attributes it to changes in NAO while we say that it is due to changes in AR regime.

So far, correlations have been computed using the occurrences of wintertime WRs, considering the higher variance and mean values of the atmospheric forc- 
ing with respect to the other seasons (Minvielle et al 2011). Using the planetary geostrophic model, we will verify that summer atmospheric dynamics play indeed a lesser role in the total interannual changes. We run two additional sensitivity experiments in which the PG model is forced with DJFM daily wind-stress and climatological values for the other months in the first one, and observed JJAS

${ }_{444}$ in $A$ have no effect, as $A$ appears in equation 5 as a multiplying factor. 


\section{Discussion and conclusion}

Since atmospheric modes of variability have been described in the literature (e.g. Barnston and Livezey 1987), many studies investigated the ocean response to those modes of variability, focussing essentially on the impact of the NAO on the circulation and hydrography in the North Atlantic. However, recent studies highlighted the role of the East-Atlantic Pattern (EAP). Msadek and Frankignoul (2009) suggest that multidecadal variability of Atlantic Meridional Overturning Circulation (AMOC) is closely related to EAP, while Langehaug et al (2012) suggest that subpolar gyre strength is significantly correlated with the EAP. Hence the EAP is at least as important as the NAO in driving variability in the North Atlantic. Nevertheless, these three studies rely on the analysis of coupled climate models which have important biases in the convection sites.

The present study is a step toward the investigation of such a relationship in observations, with a special focus laid on subtropical gyre variability. The question we address is which large-scale atmospheric pattern influences subtropical gyre variability, and through which mechanism. We use the weather regime (WR) paradigm to describe the wintertime North Atlantic atmospheric variability and investigate its impact on subtropical SSH interannual-to-decadal variability. WR treated as populations of days sharing common large-scale atmospheric circulation anomalies are different from classical modes of variability estimated for instance through EOF because they have no orthogonality constraint and account for potential spatial asymmetries of the patterns. This is especially true for $\mathrm{NAO}+$ and NAO- events and may be of central importance, as processes driving the variability of the mixed layer (turbulent and latent heat fluxes for example) are nonlinear 
(Cassou et al 2011). WRs have been shown to be efficient in capturing surface forcing variability from daily-to-interannual timescale (Cassou et al 2011).

Over the longest time period of available record over Bermuda, we find that AR is the dominant atmospheric weather regime driving SSH variability in the subtropical gyre. Sverdrup transport anomalies related to AR conditions (windstress curl changes off Europe) show a positive anomaly north of $50^{\circ} \mathrm{N}$ and a negative anomaly south of it. The dipole projects very well on the mean position of the gyres and is thus very efficient in forcing the large-scale mean circulation. We considered tide-gauge data in the Bermuda available from 1948 to 1998 and only found a significant correlation between AR WR occurrences and Bermuda SSH. The sole barely significant relationship between SSH in Bermuda and the NAO could be obtained in the framework of our study when the period is restricted to 1958-1998. This suggests that the connection between the two, if any, is not stationary, or at least not overly dominant contrary to what has been suggested in previous studies. Over a limited period of time, independent satellite observations from 1993 onwards confirm that years with frequent AR conditions in winter lead to negative SSH anomalies that encompass the full subtropical gyre, Bermuda included, suggesting a weakening of subtropical gyre strength.

We used a simple planetary geostrophic model $(\mathrm{PG})$ to explore the physical mechanisms linking wind-stress curl associated with daily wintertime WR and SSH interannual variability in Bermuda. The reconstructed signal using both the barotropic (Sverdrup like) and baroclinic (westward propagation of planetary waves) model components, which covary in phase, is highly correlated to observations suggesting that the largest part of the variability in Bermuda SSH is winddriven. Sensitivity experiments confirm that most of the interannual signal is due 
to winter wind conditions integrated over time while summer wind anomalies have

a second-order contribution to the yearly signal.

AR is closely related to the "gyre mode" defined in Hakkinen et al (2011a,b) that is linked to the second EOF mode of wind-stress curl explaining part of warm and saline intrusion from the subtropical gyre into the subpolar ocean. AR also corresponds to the positive phase of the EAP and we verify that our results are robust when using EAP time series instead of AR occurrences (correlation of -0.34 between the EAP index and Bermuda SSH anomalies instead of -0.39 for AR). Consistently with Hakkinen et al (2011a,b) our finding highlights the primarily importance of the atmospheric patterns of variability other than the NAO to understand the North Atlantic ocean dynamics.

Our study mainly focused on the immediate (0-year lag) response of subtropical SSH to changes in winter-weather regime occurrences. However, Curry and McCartney (2001) suggest that remote mechanisms, such as Eighteen Degree Water formation, Gulf-Stream intertial recirculation and deep-density structure, influence subtropical gyre variability. While remote (both in time and space) influence of NAO on ocean circulation has been thoroughly studied (Eden and Willebrand 2001; Deshayes and Frankignoul 2008), our results demonstrate that the possible influence of other modes of variability needs to be considered.

Acknowledgements NCEP Reanalysis data were provided by the NOAA/OAR/ESRL PSD, Boulder, Colorado, USA, from their Web site (http://www.esrl.noaa.gov/psd/). The altimeter products were produced by Ssalto/Duacs and distributed by Aviso, with support from Cnes (http://www.aviso.oceanobs.com/duacs/). Tide gauge data were obtained from the Permanent Service For Mean Sea Level website (http://www.psmsl.org/). 
The authors acknowledge Cécile Cabanes for having provided us the matlab routines of the baroclinic component of her model and for fruitful discussions.

Nicolas Barrier is supported by a PhD grant from Unniversité de Bretagne Occidentale,

Ifremer and Europôle Mer.

Anne-Marie Treguier, Christophe Cassou and Julie Deshayes acknowledge the CNRS.

\section{References}

Antonov J, Locarnini R, Boyer T, Mishonov A, Garcia H (2006) World Ocean Atlas 2005, Volume 2: Salinity. NOAA Atlas NESDIS 62

Ayrault F, Lalaurette F, Joly A, Loo C (1995) North-Atlantic Ultra-High Frequency variabilityAn introductory survey. Tellus Series A-Dynamic Meteorology and Oceanography 47(5, Part 1):671-696

Barnston A, Livezey R (1987) Classification, seasonality and persistence of low-frequency atmospheric circulation patterns. Monthly Weather Review 115(6):1083-1126

Bindoff N, Willebrand J, Artale V, A C, Gregory J, Gulev S, Hanawa K, Qur CL, Levitus S, Nojiri Y, Shum C, Talley L, Unnikrishnan A (2007) Observations: Oceanic Climate Change and Sea Level. Climate Change 2007: The Physical Science Basis Contribution of Working Group I to the Fourth Assessment Report of the Intergovernmental Panel on Climate Change

Bretherton C, Widmann M, Dymnikov V, Wallace J, Blade I (1999) The effective number of spatial degrees of freedom of a time-varying field. Journal of Climate 12(7):1990-2009

Cabanes C, Huck T, De Verdiere AC (2006) Contributions of wind forcing and surface heating to interannual sea level variations in the Atlantic Ocean. Journal of Physical Oceanography 36(9):1739-1750

Cassou C (2008) Intraseasonal interaction between the Madden-Julian Oscillation and the North Atlantic Oscillation. Nature 455(7212):523-527

Cassou C, Terray L, Hurrell J, Deser C (2004) North Atlantic winter climate regimes: Spatial asymmetry, stationarity with time, and oceanic forcing. Journal of Climate 17(5):10551068 
Cassou C, Minvielle M, Terray L, Perigaud C (2011) A statistical-dynamical scheme for reconstructing ocean forcing in the Atlantic. Part I: weather regimes as predictors for ocean surface variables. Climate Dynamics 36(1-2):19-39

Cayan D (1992) Latent and sensible heat-fluxes anomalies over the Northern Oceans - Driving the Sea-Surface Temperature. Journal of Climate 5(4):354-369

Chelton D, DeSzoeke R, Schlax M, El Naggar K, Siwertz N (1998) Geographical variability of the first baroclinic Rossby radius of deformation. Journal of Physical Oceanography 28(3):433-460

Compo GP, Whitaker JS, Sardeshmukh PD, Matsui N, Allan RJ, Yin X, Gleason BE Jr, Vose RS, Rutledge G, Bessemoulin P, Broennimann S, Brunet M, Crouthamel RI, Grant AN, Groisman PY, Jones PD, Kruk MC, Kruger AC, Marshall GJ, Maugeri M, Mok HY, Nordli O, Ross TF, Trigo RM, Wang XL, Woodruff SD, Worley SJ (2011) The Twentieth Century Reanalysis Project. Quaterly Journal of the Royal Meteorological Society 137(654, Part a): $1-28$

Curry R, McCartney M (2001) Ocean gyre circulation changes associated with the North Atlantic Oscillation. Journal of Physical Oceanography 31(12):3374-3400

Curry R, McCartney M, Joyce T (1998) Oceanic transport of subpolar climate signals to mid-depth subtropical waters. Nature 391(6667):575-577

Deshayes J, Frankignoul C (2008) Simulated variability of the circulation in the North Atlantic from 1953 to 2003. Journal of Climate 21(19):4919-4933

Ducet N, Le Traon P, Reverdin G (2000) Global high-resolution mapping of ocean circulation from TOPEX/Poseidon and ERS-1 and-2. Journal of Geophysical Research-Oceans 105(C8):19,477-19,498

Eden C, Willebrand J (2001) Mechanism of interannual to decadal variability of the North Atlantic circulation. Journal of Climate 14(10):2266-2280

Esselborn S, Eden C (2001) Sea surface height changes in the North Atlantic Ocean related to the North Atlantic Oscillation. Geophysical Research Letters 28(18):3473-3476

Ezer T (1999) Decadal variabilities of the upper layers of the subtropical North Atlantic: An ocean model study. Journal of Physical Oceanography 29(12):3111-3124 
Frankignoul C, Muller P, Zorita E (1997) A simple model of the decadal response of the ocean to stochastic wind forcing. Journal of Physical Oceanography 27(8):1533-1546

Gulev S, Jung T, Ruprecht E (2002) Climatology and interannual variability in the intensity of synoptic-scale processes in the North Atlantic from the NCEP-NCAR reanalysis data. Journal of Climate 15(8):809-828

Gulev S, Barnier B, Knochel H, Molines J, Cottet M (2003) Water mass transformation in the North Atlantic and its impact on the meridional circulation: Insights from an ocean model forced by NCEP-NCAR reanalysis surface fluxes. Journal of Climate 16(19):3085-3110

Hakkinen S (1999) Variability of the simulated meridional heat transport in the North Atlantic for the period 1951-1993. Journal of Geophysical Research-Oceans 104(C5):10,991-11,007

Hakkinen S, Rhines PB, Worthen DL (2011a) Atmospheric Blocking and Atlantic Multidecadal Ocean Variability. Science 334(6056):655-659

Hakkinen S, Rhines PB, Worthen DL (2011b) Warm and saline events embedded in the meridional circulation of the northern North Atlantic. Journal of Geophysical Research 116

Hong B, Sturges W, Clarke A (2000) Sea level on the US East Coast: Decadal variability caused by open ocean wind-curl forcing. Journal of Physical Oceanogaphy 30(8):2088-2098

Hurrell J (1995) Decadal Trends in the North-Atlantic Oscillation - Regional temperatures and precipitations. Science 269(5224):676-679

Hurrell J, VanLoon H (1997) Decadal variations in climate associated with the north Atlantic oscillation. Climatic Change 36(3-4):301-326

Joyce T, Deser C, Spall M (2000) The relation between decadal variability of subtropical mode water and the North Atlantic Oscillation. Journal of Climate 13(14):2550-2569

Kalnay E, Kanamitsu M, Kistler R, Collins W, Deaven D, Gandin L, Iredell M, Saha S, White G, Woollen J, Zhu Y, Chelliah M, Ebisuzaki W, Higgins W, Janowiak J, Mo K, Ropelewski C, Wang J, Leetmaa A, Reynolds R, Jenne R, Joseph D (1996) The NCEP/NCAR 40-year reanalysis project. Bulletin of the American Meteorological Society 77(3):437-471

Langehaug HR, Medhaug I, Eldevik T, Ottera OH (2012) Arctic/Atlantic Exchanges via the Subpolar Gyre. Journal of Climate 25(7):2421-2439

Locarnini R, Mishonov J AVand Antonov, Boyer T, Garcia H (2006) World Ocean Atlas 2005, Volume 1: Temperature. NOAA Atlas NESDIS 61 
Lohmann K, Drange H, Bentsen M (2009) Response of the North Atlantic subpolar gyre to persistent North Atlantic oscillation like forcing. Climate Dynamics 32(2-3):273-285

Michelangi P, Vautard R, Legras B (1995) Weather Regimes - Recurrence and quasistationarity. Journal of Atmospheric Sciences 52(8):1237-1256

Minvielle M, Cassou C, Bourdalle-Badie R, Terray L, Najac J (2011) A statistical-dynamical scheme for reconstructing ocean forcing in the Atlantic. Part II: methodology, validation and application to high-resolution ocean models. Climate Dynamics 36(3-4):401-417

Molteni F, Tibaldi S, Palmer T (1990) Regimes in the wintertime circulation over northren extratropics .1. Observational Evidence. Quaterly Journal of the Royal Meteorological Society 116(491, Part a):31-67

Msadek R, Frankignoul C (2009) Atlantic multidecadal oceanic variability and its influence on the atmosphere in a climate model. Climate Dynamics 33(1):45-62

Ponte R (2006) Low-frequency sea level variability and the inverted barometer effect. Journal of Atmospheric and Oceanic Technology 23(4):619-629

Rudeva I, Gulev SK (2011) Composite Analysis of North Atlantic Extratropical Cyclones in NCEP-NCAR Reanalysis Data. Monthly Weather Review 139(5):1419-1446

Santos J, Corte-Real J, Leite S (2005) Weather regimes and their connection to the winter rainfall in Portugal. International Journal of Climatology 25(1):33-50

Smyth P, Ide K, Ghil M (1999) Multiple regimes in Northern Hemisphere height fields via mixture model clustering. Journal of the Atmospheric Sciences 56(21):3704-3723

Stammer D, Agarwal N, Herrmann P, Koehl A, Mechoso CR (2011) Response of a Coupled Ocean-Atmosphere Model to Greenland Ice Melting. Surveys in Geophysics 32(4-5, SI):621-642

von Storch H (1999) On the use of "inflation" in statistical downscaling. Journal of Climate 12(12):3505-3506

Sturges W, Hong B (1995) Wind forcing of the Atlantic Thermocline along 32 degrees N at low frequencies. Journal of Physical Oceanography 25(7):1706-1715

Sturges W, Hong B, Clarke A (1998) Decadal wind forcing of the North Atlantic subtropical gyre. Journal of Physical Oceanography 28(4):659-668 
Tsimplis M, Shaw A, Flather R, Woolf D (2006) The influence of the North Atlantic Oscillation on the sea-level around the northern European coasts reconsidered: the thermosteric effects. Philosophical Transactions of the Royal Society A-Mathematical Physical and Engineering Sciences 364(1841):845-856

Tsimplis MN, Shaw AGP (2008) The forcing of mean sea level variability around Europe. Global and Planetary Change 63(2-3, SI):196-202

Vautard R (1990) Multiple weather regimes over the North-Atlantic. Analysis of precursors and successors. Monthly Weather Review 118(10):2056-2081

Vautard R, Legras B (1988) On the source of midlatitude low-frequency variability. Part 2: Nonlinear equilibration of Weather Regimes. Journal of Atmospheric Sciences 45(20):28452867

Woodworth P, Pouvreau N, Woeppelmann G (2010) The gyre-scale circulation of the North Atlantic and sea level at Brest. Ocean Science 6(1):185-190 

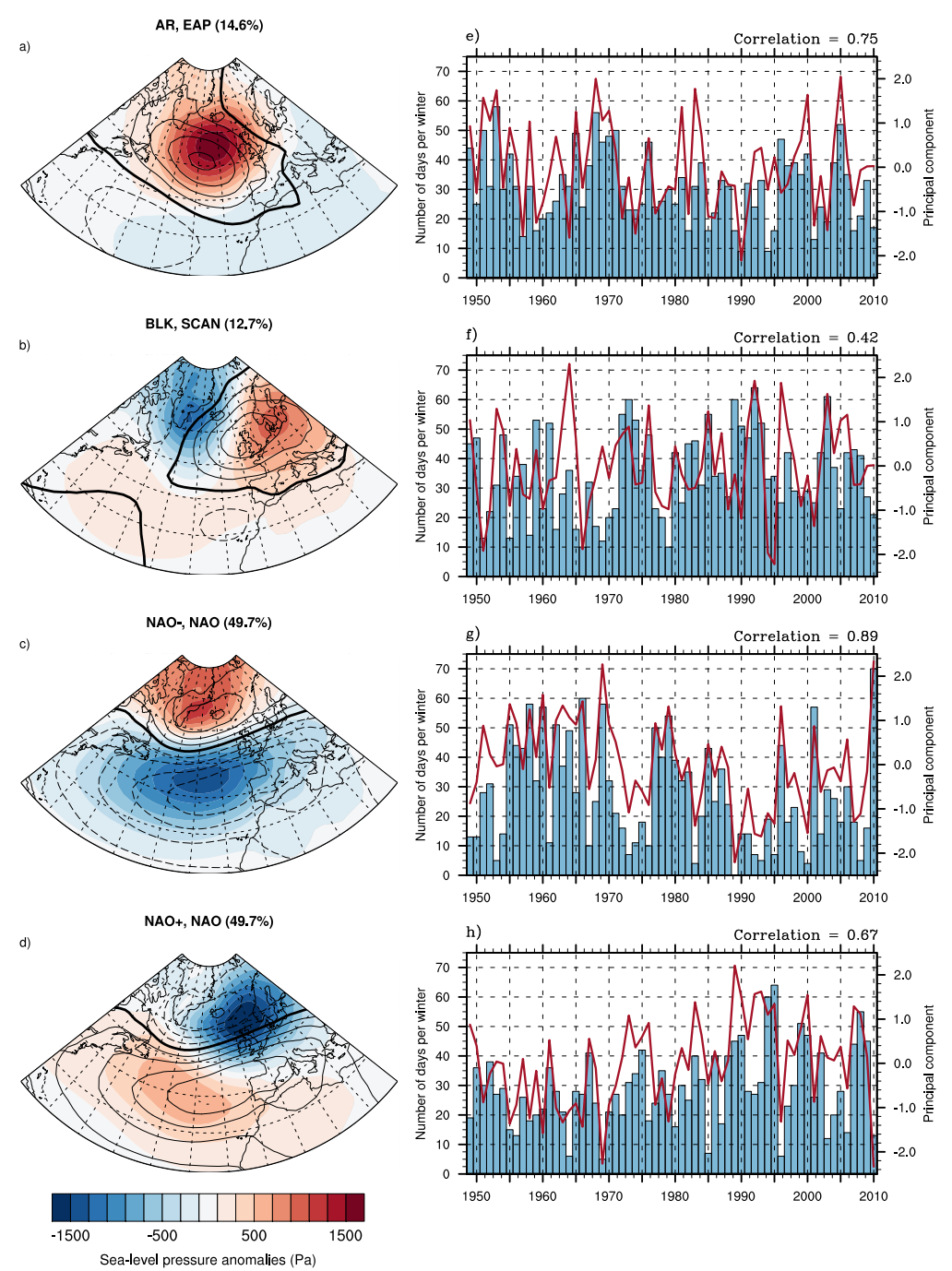

Fig. 1: (left) Centroids of daily sea-level pressure anomalies for the four weather regimes (colors, contour interval: $200 \mathrm{~Pa}$ ) and EOF-derived modes of variability computed from DJFM averaged sea-level pressure anomalies (black contours, contour interval: $50 \mathrm{~Pa}$ ). The variance explained by each EOF is indicated between parenthesis. (right) Number of days per winter of WR winter occurrences (bars) and corresponding principal components (PC) from EOF (see text for details). The correlations between the occurrences and the PCs are indicated. For panel c), the $\mathrm{NAO}_{E O F}$ pattern and associated $\mathrm{PC}$ are multiplied by -1 so that they share the same sign as the NAO- regime. 


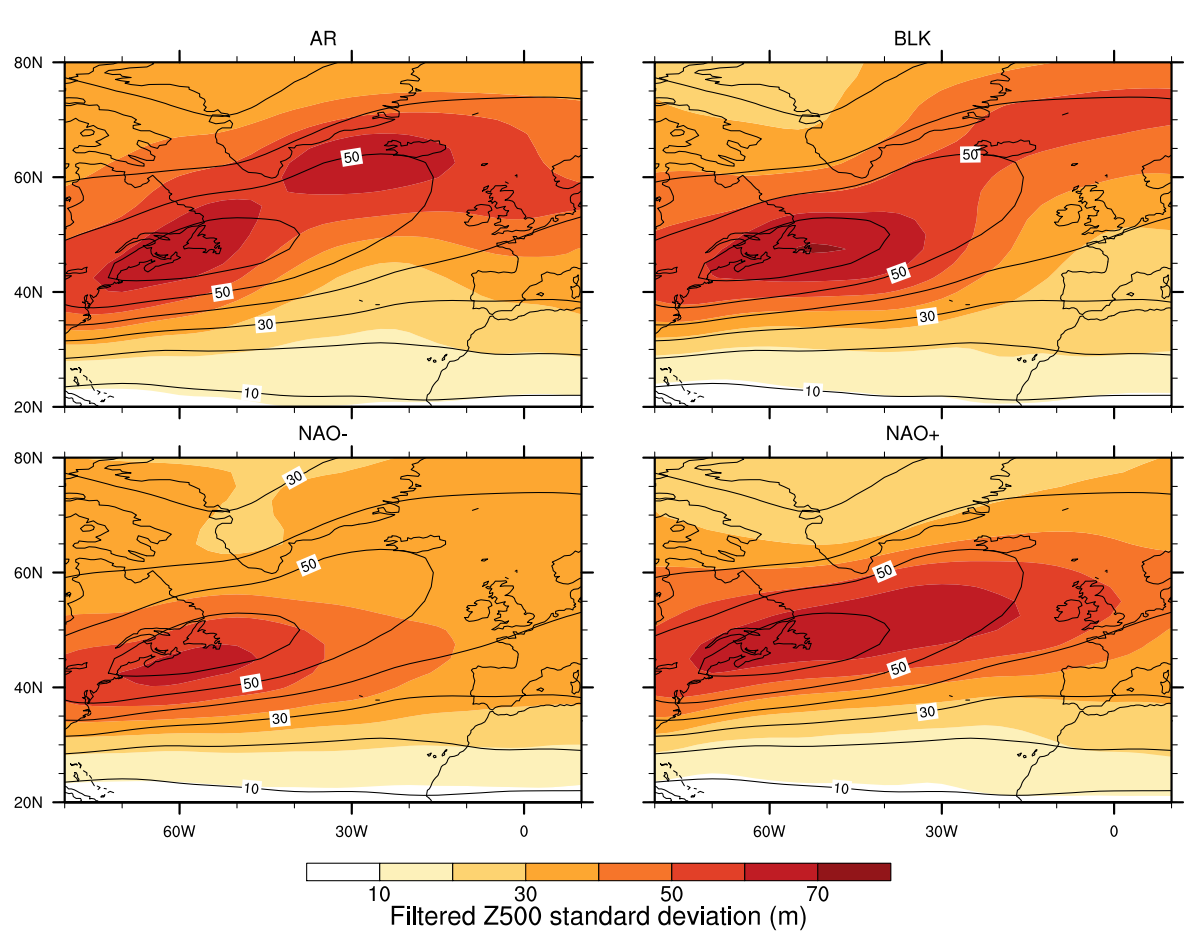

Fig. 2: Daily DJFM standard deviation of filtered $\left(2-6\right.$ days) $Z_{500}$ anomalies (black contours: climatological, color shading: within each weather regime) 


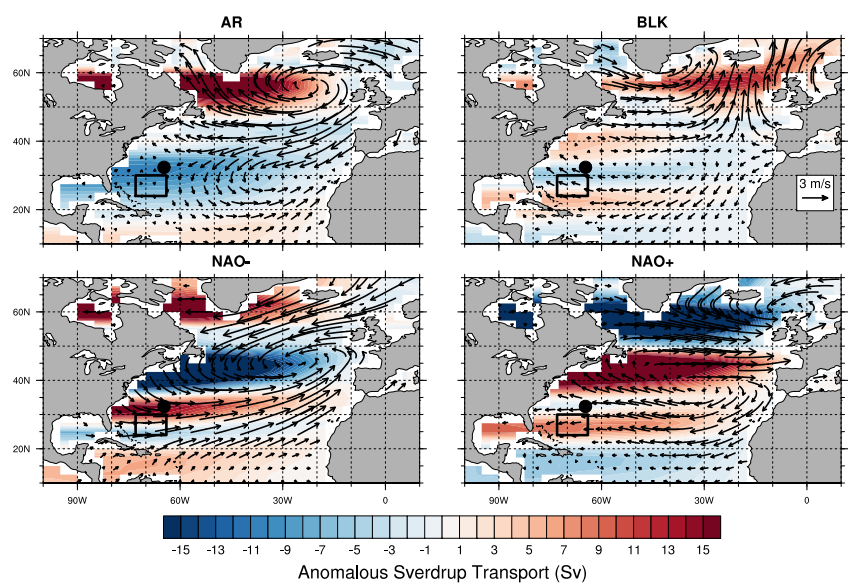

Fig. 3: Daily composites of winter wind-field anomalies (arrows, reference $=$ $3 \mathrm{~m} . \mathrm{s}^{-1}$ ) and corresponding anomalous Sverdrup transport (colors, contour interval $=1 S v$ ). The black point shows the location of the Esso-Pier (Bermuda) station and the black rectangle our subtropical box used in the correlation (see text and table 1).

Table 1: List of correlations cited in the text. "AR-induced SSH" refers to the regressed reconstructed series (solid line in fig 5) and "PG model" refers to the linear solution calculated from daily wind fields (dashed line in figure 5 and black line in figure 6).

\begin{tabular}{|c|c|c|c|c|c|}
\hline \multicolumn{2}{|c|}{ Time series } & Period & Confidence interval & Correlation \\
\hline \hline AR winter occurrences & vs & Subtropical AVISO MADT & $1993-2009$ & $80 \%$ & -0.34 \\
\hline AR winter occurrences & vs & Observed Bermuda SSH & $1949-1998$ & $95 \%$ & -0.39 \\
\hline AR-induced SSH & vs & Observed Bermuda SSH & $1949-1998$ & $95 \%$ & 0.39 \\
\hline PG model & vs & Observed Bermuda SSH & $1954-1998$ & $95 \%$ & 0.53 \\
\hline AR winter occurrences & vs & PG model & $1954-2006$ & $95 \%$ & -0.53 \\
\hline
\end{tabular}




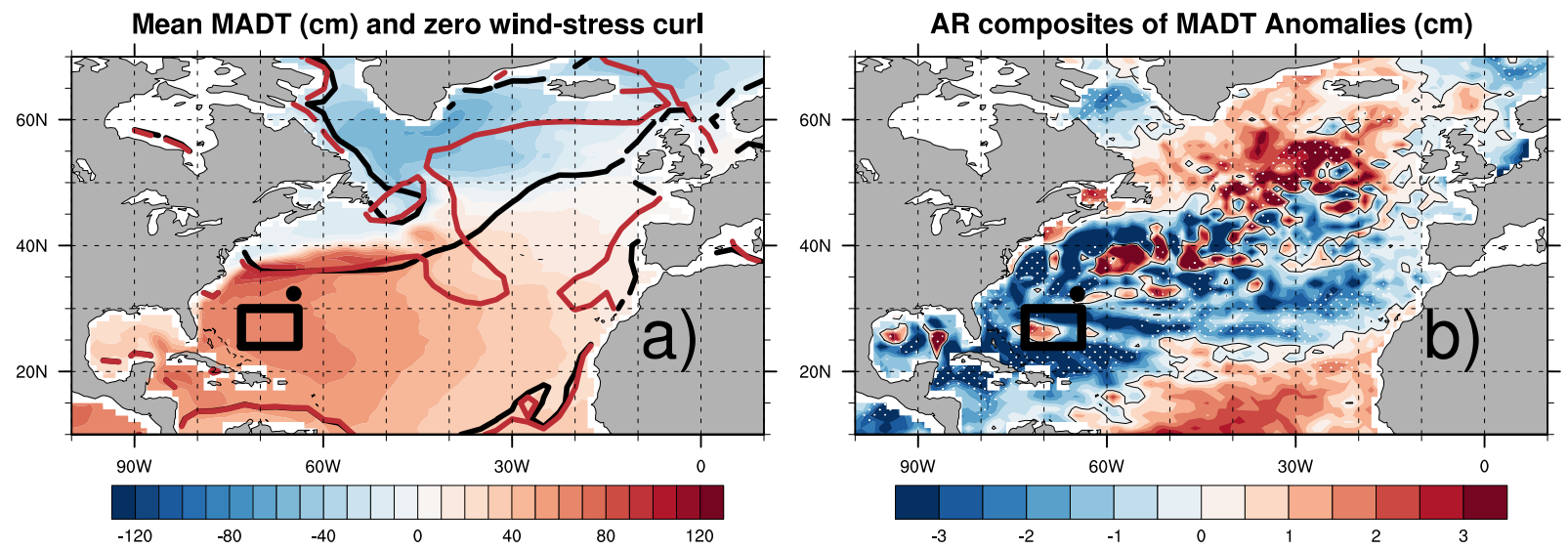

Fig. 4: (Left) Mean Map of Absolute Dynamic Topography (colors). Climatological

(black contours) and AR composite (red contours) zero wind-stress curl. (Right)

panel: Map of Absolute Dynamic Topography (MADT) anomalies composite for extreme Atlantic Ridge events (zero contours are depicted in black). Significant values, based on t-statistics at the $80 \%$ level of confidence, are white dotted. 


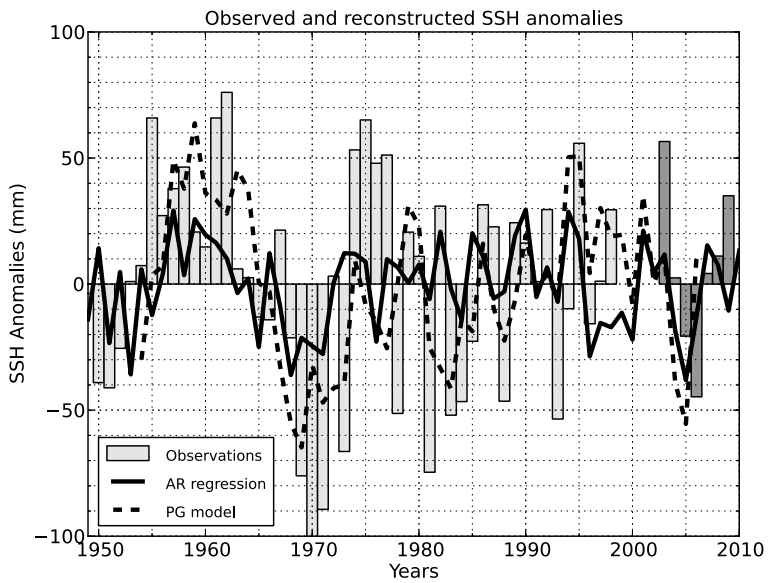

Fig. 5: Observed time-series of Bermuda Sea-Surface Height anomalies (in mm, light grey bars are the tide-gauge observations used in the regression while dark gray bars are independent tide-gauge observations), regressed SSH onto AR occurrences (solid line) and the planetary geostrophic model of sea-level (dashed line). 


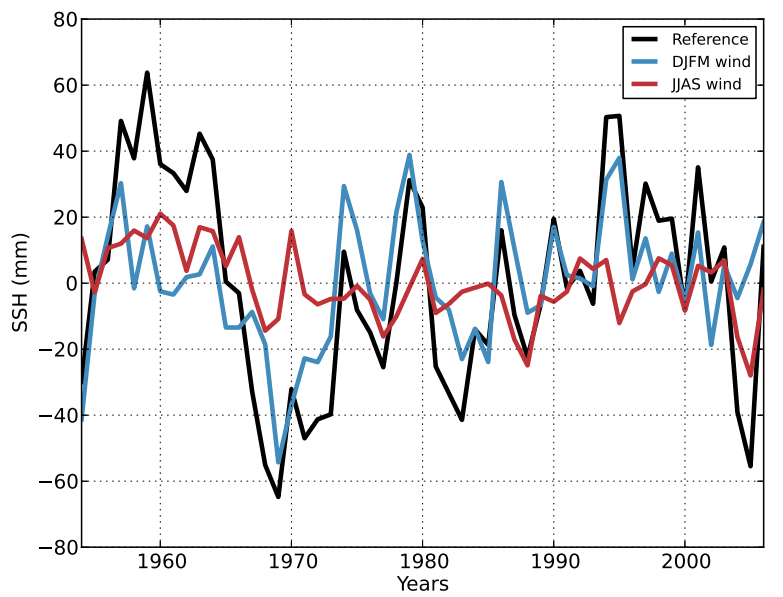

Fig. 6: Planetary geostrophic model forced by observed wind (black) and sensitivity experiments with variable DJFM wind only (blue) and variable JJAS wind only (red) 